\title{
EFFECTS OF ELEVATED BODY TEMPERATURE ON CONTROL OF BREATHING
}

\author{
Zila I., Calkovska A.
}

Department of Physiology, Jessenius Faculty of Medicine, Comenius University, Martin, Slovak Republic

\begin{abstract}
Changes in body temperature can be evoked mainly by alterations in the peripheral temperature, or modified by shifts in the central body temperature. Two conditions can lead to abnormal elevation of body temperature: hyperthermia or fever. As regards respiratory system, exposure to heat stress is accompanied by marked alterations in breathing, especially by an increase in ventilation. Ventilation rises due to an increase in central output from hypothalamus or brainstem, an increase in peripheral output via skin temperature receptors, an increase in central or/and peripheral chemoreceptor output or sensitivity and can be also mediated through changes in thermoregulatory mechanisms.

This review summarizes results of previous studies as well as of experiments done in our laboratory in order to elucidate the mechanisms included in respiratory changes under heat stress.
\end{abstract}

Key words: heat stress, fever, hyperthermia, control of breathing

\section{INTRODUCTION}

Exposure to heat stress is accompanied by an increase in ventilation irrespective of a reason of elevated body temperature. Despite of low metabolic demands, hyperthermia and fever are accompanied by an increase in pulmonary ventilation (1). For this reason, a heat-mediated increase in ventilation must be caused by a change in sensitivity and/ or activity of neural and/or chemical respiratory control and by its altered interaction with thermoregulation.

The aim of this review is to present and summarize the insights into the interaction between thermoregulation and control of breathing and to discuss recently suggested mechanisms in the light of current literature and the results of our experimental studies.

\section{Thermoregulation and abnormal elevation of body temperature}

Body temperature is closely regulated by homeostatic mechanisms that strike a balance between heat production and heat dissipation (2). Heat is a product of all metabolic processes and it is dissipated over the body surface. The skin accounts for about 90\% of heat loss, with the lungs contributing most of the remaining $10 \%$. In the basal state, about $70 \%$ of the body's thermal load is dissipated by conduction; $30 \%$ is removed by the evaporation of insensible perspiration. Radiation and convection are less important mechanisms of heat removal. When the ambient temperature rises or metabolic heat production increases, evaporation accounts for the major share of heat dissipation (3). In humans, controlling centre for thermoregulation is located in hypothalamus. Hypothalamus detects changes in the body's thermal state directly from changes in blood temperature and indirectly by peripheral inputs from thermosensitive receptors located in the skin and in the muscles (4). The preoptic nucleus of the anterior hypothalamus functions as the thermal control centre and acts to maintain the body temperature at a set value. Thus, it serves as so-called hypothalamic thermal set point (5).

Abnormal elevation of body temperature, or pyrexia, can occur as a result of hyperthermia or fever. In hyperthermia, thermal control mechanisms fail, so that heat production

Address for correspondence:

Ivan Zila, MD, PhD, Department of Physiology; Jessenius Faculty of Medicine; Comenius University

Mala Hora 4, 03601 Martin, Slovakia, Phone/fax: 00421-43-4131426; zila@jfmed.uniba.sk 
exceeds heat dissipation. The most important clinical causes of severe hyperthermia are heatstroke, neuroleptic syndrome, and malignant hyperthermia of anesthesia. Experimental hyperthermia is usually performed by body surface heating using a heating pad and radiant heat from an infrared lamp.

In contrast, in fever, the hypothalamic thermal set point rises, and intact thermal control mechanisms are involved to rise body temperature up to the new set point (3). In febrile response, body temperature is raised by both increased heat production and decreased heat loss (6). A classical model of fever pathogenesis implies a direct effect of various pyrogens on hypothalamus to elevate the thermal set point (7) (Fig.1). Experimentally, fever can be induced with a bolus injection of pyrogenic substance to laboratory animals. Administration of commonly used lipopolysaccharide (LPS) results in mono- or polyphasic body temperature rise and other inflammatory sequels of infection (6). It is generally considered that LPS-induced fever is mediated by production of cytokines (interleukin $1 \beta$ and 6 ) and subsequent induction of prostaglandine E2 as a central mediator of fever in hypothalamus. Features of experimental fever strongly depend on several critical factors: the serotype of lipopolysaccharide, the dose and the way of administration (7).

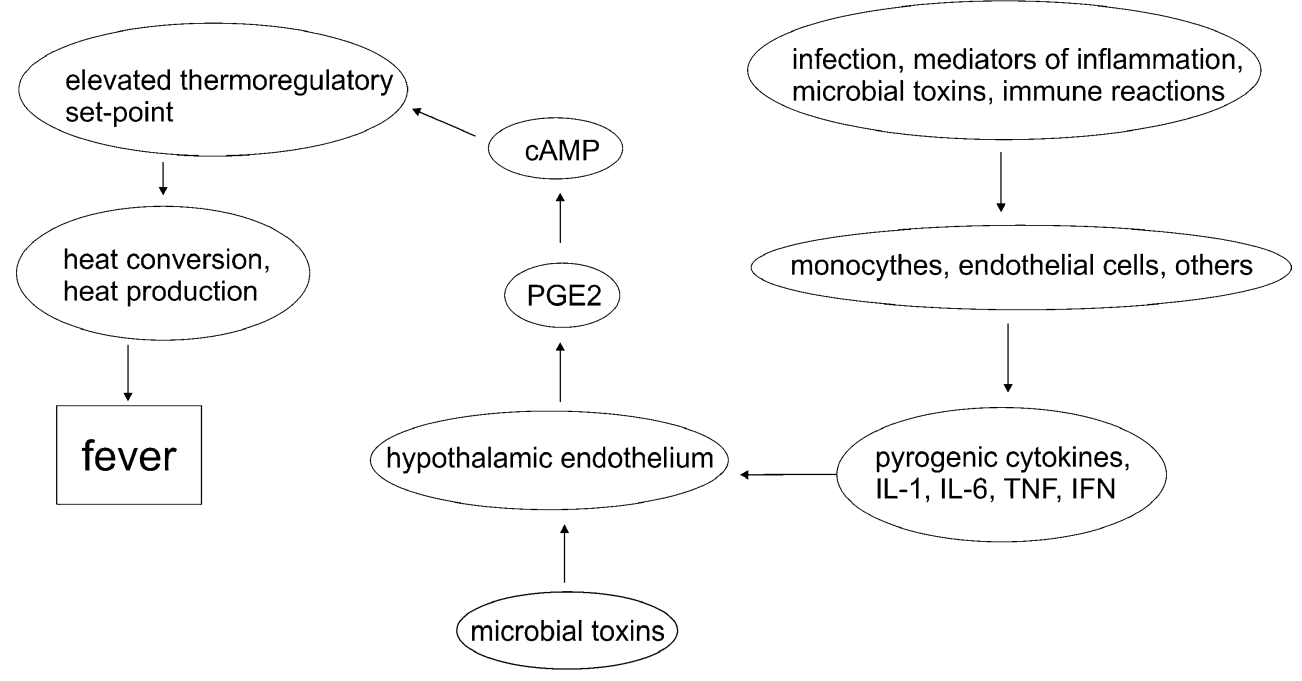

Fig. 1 Events in the course of fever induction

\section{Breathing pattern and neural control in thermal stress}

The body temperature changes are accompanied with marked alterations in breathing pattern. These changes are evoked by alterations in the peripheral temperature, or modified by shifts in the central body temperature, eventually by other mechanisms. Hyperpnoea associated with elevated core temperature was described for the first time by Haldane in 1905 (8) and since then numerous studies have been focused on investigation of breathing control in elevated-body temperature conditions. For many animals an elevation in body temperature enhances respiratory frequency but decreases inspiratory amplitude and its duration. The increase in respiration helps to cool the body and restore its temperature to a normal range. In fact, the temperature-dependent modulation of respiratory frequency (e.g. panting) is a major mechanism to dissipate heat and avoid heat-stroke.

What are the mechanisms that mediate the hyperthermic hyperventilation ? The scale is extensive as hyperventilation was shown to be mediated by increase output from structures of central nervous system, through increase in peripheral output from skin recep- 
tors, by increases in output of central or/and peripheral chemoreceptors or changes in their sensitivity and through changes in thermoregulatory mechanisms (9 - 12) (Fig. 2).

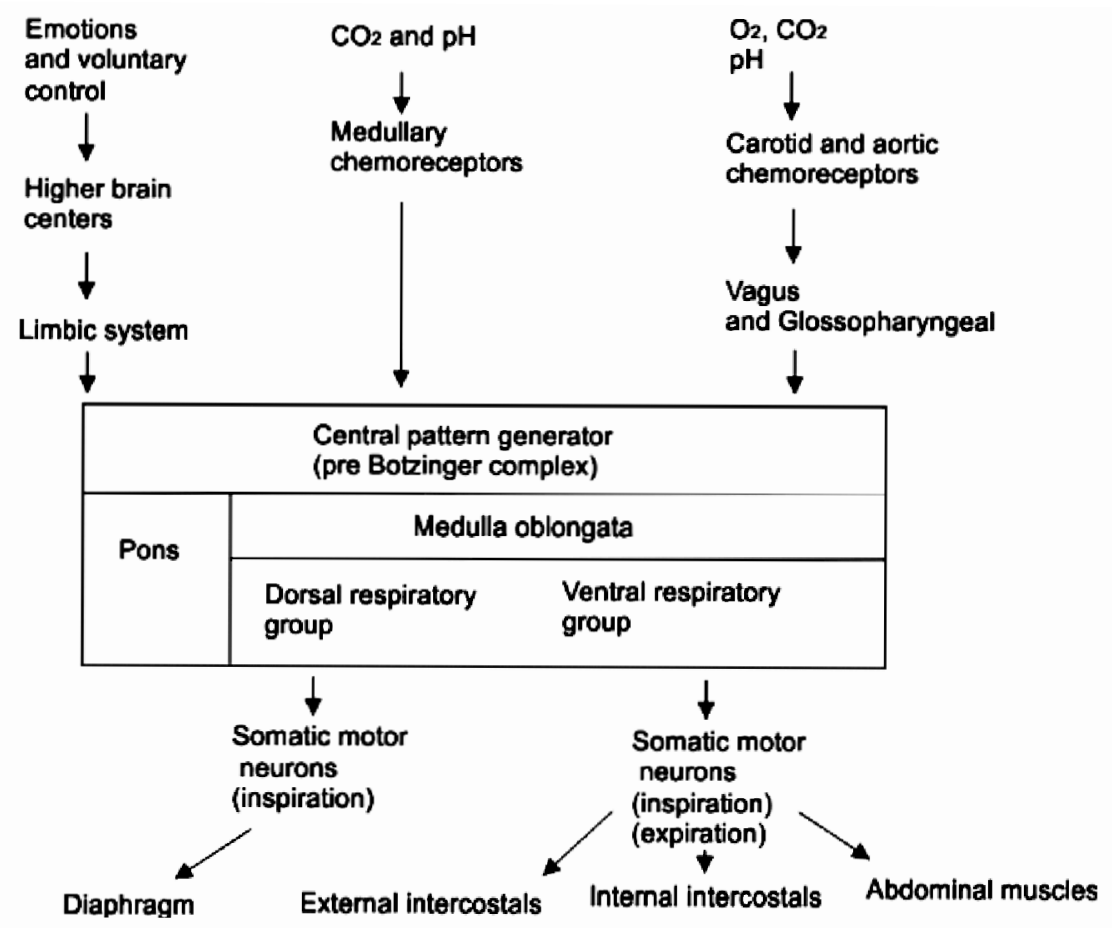

Fig. 2 Sensors, centres and effectors involved in control of breathing

Several studies confirmed a crucial role of hypothalamus in modulating respiratory frequency with changes in body temperature (13 -15). In some species, a specialized breathing pattern known as panting is mediated by the thermoregulatory system in the preoptic area of the hypothalamus. However, temperature can also directly affect the activity of the respiratory neural network located in the medulla. For instance, area of pre-Bötzinger complex was suggested to play critical role in a change of breathing pattern during thermal stress (16). Direct effect of endotoxin on respiratory centres should also be considered. It was reported that endotoxin may induce alterations in respiratory motor output independently of fever response (17). Saxton (18) documented hyperventilation associated with a reduction in end-tidal $\mathrm{PCO}_{2}$ in heat stressed subjects suggesting two major reasons of altered breathing pattern: first, a change in sensitivity of central chemoreceptors and second, a change in the threshold of that response.

Besides central mechanisms, elevated body temperature can evoke a change of breathing pattern also by peripheral feedback control or by a combination of both. Slowly adapting pulmonary stretch receptors and vagal afferent fibres from lungs play an important role in the regulation of respiration rate and tidal volume in mammals (19). Activation of pulmonary slowly adapting stretch receptors elicits Hering-Breuer reflex, that is defined by inhibition of inspiratory and prolongation of expiratory phases of respiratory cycle (20). Crucial importance of this reflex is to accomplish inspiratory to expiratory switching and to prevent overinflation of the lungs. Under conditions of thermal stress, a contribution of this control varies among species $(10,19,21-23)$ as enhanced 
sensitivity and increased response of Hering-Breuer reflex were found in rats exposed to progressive hyperthermia (24), but not in rabbits (10).

During fever, besides apparent thermal response, a direct effect of endotoxin on vagal sensory receptors of the airways and lungs must be considered. Our data have shown that both the strength and duration of Hering-Breuer reflex were reduced in rats during fever response (25). Endotoxemia is known to cause the local release of various chemical mediators in lung tissues and produces bronchoconstriction, increased lung stiffness, and tissue edema (26). It is possible that these endotoxin-induced consequences may serve as chemical and mechanical stimuli to activate lung vagal sensory receptors. Several investigators (27-32) have suggested that various local or reflex pulmonary responses to endotoxin are linked to the stimulation of lung vagal sensory receptors included C-fibres.

\section{Chemical control of breathing in thermal stress}

Chemical control of breathing involves a complex interaction of central and peripheral sensors, integrating centre and effector system (33). A direct effect of elevated temperature on the chemoreceptors can induce heat-hyperpnea. However, it is difficult to directly measure chemoreceptor output in response to thermal stress (9). Direct heating of central chemoreceptors led to decrease in minute ventilation in cats (34). Electrophysiological studies have revealed that carotid body activity increases with increasing temperature (35 - 39). This thermal sensitivity is high and hyperthermia, like hypoxia, increases carotid chemoreceptor $\mathrm{CO}_{2}$ sensitivity (40). As an alternative approach, in most of studies a measurement and an analysis of ventilatory responses to hypoxia or/ and hypercapnia have been applied.

Hypercapnic ventilatory response (HCVR) is mediated by both, central and peripheral chemoreceptors. While the model of central chemoreflex is expressed as a straight-line relation between the ventilatory response and the arterial level of carbon dioxide, the peripheral chemoreceptors are complex sensors and their sensitivity to carbon dioxide is controlled by hypoxia in a non-linear way. This physiological concept of chemical control mechanisms illustrates methodological complexity of chemoreflexes measurement. Investigation of HCVR mediated by central chemoreceptors has brought contradictory observations. Some authors have found increased central chemoreflex sensitivity (4144), but other studies have not confirmed any change in sensitivity of central chemoreceptors under conditions of thermal stress (e.g. 45). In some experiments, a decrease of HCVR in a warm environment was observed (46). There are several possible reasons for contradictory observations, among them the different methods of investigation seem to be the most feasible. Recently, it has been proposed that hyperventilation accompanying heat stress is associated with an increase in chemoreceptor sensitivity $(47,48)$. Some authors suggest an interaction between thermal and central chemoreceptor drives to breathe (41). This relation is multiplicative rather than additive. There is also an additive ventilatory drive component due to thermal stimuli independent of carbon dioxide. The role of thermoregulatory structures as a possible place of interaction hypercapnia/ hyperthermia is still questionable, and the results differ in dependence of animal species. While in cats an increased activity of central thermoreceptors during hypercapnia was found (49), in hamsters the activity of preoptic thermosensitive neurons decreased with a rise of $\mathrm{CO}_{2}$ (50). Berquin et al. (51) identified also caudal hypothalamus as a site of central hypercapnic chemoreception that extends the possibilities where an interaction between an elevated body temperature and hypercapnia takes place.

Ventilatory responses to hypoxia (HVR) are mediated primarily by the carotid bodies $(90 \%)$ and partially by the aortic bodies (10\%) (52). Previous works on animals have shown a larger increase in ventilation to a given hypoxic stimulus during elevated body temperature $(53,54)$. However, Watanabe and co-authors (55) have shown that respiratory response mediated via peripheral chemoreceptors decreases in higher environmen- 
tal temperature in kittens. It is probable that the metabolic rate reduction leads to lower amplitude of oscillation in $\mathrm{PaCO}_{2}$, and thus to lower intensity of respiratory response to hypoxia. Similar inhibition of isocapnic HVR was observed in hyperthermic rabbits (56). Only few studies have investigated HVR under conditions of thermal stress in man and data has shown augmented HVR sensitivity, but also large inter-individual variability associated with HVR test $(57,58)$. Therefore, recently recommended HVR method may allow more detailed assessment of ventilatory responses mediated by peripheral chemoreceptors as well as easier comparisons of results and help to avoid methodological discrepancies (59).

\section{Conclusion}

It becomes clear that changes in respiratory control and in thermoregulation affect each other. Heat stress strongly affects the ventilation as a result of additive and maybe multiplicative responses of neural and chemical control loops. Up to now, these interactions are not satisfactory clarified and a lot of work still must be done in this field. Theoretically, such effects could give rise to failure of the respiratory system and there is some circumstantial evidence to support the concept that on occasions such interactions may be of importance in sudden unexpected death in infancy.

\section{REFERENCES}

1. Cabanac M, White MD. Core temperature thresholds for hyperpnea during passive hyperthermia in humans. Eur J Appl Physiol Occup Physiol 1995; 71: 71-6.

2. Webb P. The physiology of heat regulation. Am J Physiol 1995; 268: R838.

3. Simon HB. Hyperthermia. N Engl J Med 1993; 329: 483-87.

4. Gisolfi CV, Wenger CB. Temperature regulation during exercise: old concepts, new ideas. Exercise and Sport Sciences Reviews 1984; 12: 339-72.

5. Boulant JA: Role of the preoptic-anterior hypothalamus in thermoregulation and fever. Clin Infect Dis 2000; 31: S157. Mackowiak PA: Concepts of fever. Arch Intern Med 1998; 158:1870.

6. Romanovsky AA, Kulchitsky VA, Simons CT, Sugimoto N. Methodology of fever research: why are polyphasic fevers often thought to be biphasic? Am J Physiol 1998; (1 Pt 2): R332-8.

7. Dogan DM, Ataoglu H, Akarsu ES. Effects of different serotypes of Escherichia coli lipopolysaccharides on body temperature in rats. Life Sciences 2000; 67: 2319-29.

8. Haldane JS. The influence of high air temperatures. Journal of Hygiene 1905; 55: 497-513.

9. Plevková J, Brozmanová M, Tatár M. The effect of intensified nasal breathing on the cough reflex intensity in Guinea pigs with ovalbumin induced rhinitis. Acta Med Mart 2004; 4(2): 3-11.

10. Javorka K, Calkovska A, Petraskova M, Gecelovska V. Cardiorespiratory parameters and respiratory reflexes in rabbits during hyperthermia. Physiol Res 1996; 45(6): 439-47.

11. Brozmanova A, Jochem J, Javorka K, Zila I, Zwirska-Korczala K. Effects of diuretic-induced hypovolemia/ isosmotic dehydration on cardiorespiratory responses to hyperthermia and its physical treatment in rabbits. Int J Hyperthermia 2006; 22: 135-47.

12. Brozmanova A, Jochem J, Javorka K, Zila I, Zwirska-Korczala K. Diuretic-induced dehydration/ hypovolemia inhibits thermal panting in rabbits. Respir Physiol Neurobiol 2006; 1: 99-102.

13. Boden AG, Harris MC, Parkes MJ. The preoptic area in the hypothalamus is the source of the additional respiratory drive at raised body temperature in anaesthetised rats. Exp Physiol 2000; 85(5): 527-37.

14. Inomoto $\mathrm{T}$, Mercer $\mathrm{JB}$, Simon $\mathrm{E}$. Interaction between hypothalamic and extrahypothalamic body temperatures in the control of panting in rabbits. Pflugers Arch 1983; 398(2): 142-6.

15. Ni H, Schechtman VL, Zhang J, Glotzbach SF, Harper RM. Respiratory responses to preoptic/anterior hypothalamic warming during sleep in kittens. Reprod Fertil Dev 1996; 8(1): 79-86.

16. Tryba AK, Ramirez JM. Hyperthermia modulates respiratory pacemaker bursting properties. J Neurophysiol 2004; 92(5): 2844-52.

17. Preas HL 2nd, Jubran A, Vandivier RW, Reda D, Godin PJ, Banks SM, Tobin MJ, Suffredini AF. Effect of endotoxin on ventilation and breath variability: role of cyclooxygenase pathway. Am J Respir Crit Care Med 2001; 164(4): 620-6.

18. Saxton C. Effects of severe heat stress on respiration and metabolic rate in resting man. Aviat Space Environ Med 1981; 52(5): 281-6. 
19. Poliaček I, Jakuš J, Halašová E, Baráni H, Muríň P, Bolser D. Defensive airway reflexes induce widely spreading Fos labelling in the cat brainstem. Acta Med Mart 2008; 8(2): 3-15.

20. Breuer J. Self-steering of respiratiom through the nerves vagus. In: R. Porter (Ed.), Breathing: HeringBreuer Centenary Symposium, 1868, Churchill 1970; 365-394.

21. Bradley GW, von Euler C, Marttila I, Roos B. Steady state effects of $\mathrm{CO}_{2}$ and temperature on the relationship between lung volume and inspiratory duration (Hering-Breuer threshold curve). Acta Physiol Scand 1974; 92(3): 351-63.

22. Merazzi D, Mortola JP. Hering-Breuer reflex in conscious newborn rats: effect of changes in ambient temperature during hypoxia. J Appl Physiol 1999; 87(5): 1656-61.

23. Werner MF, Fraga D, Melo MC, Souza GE, Zampronio AR. Importance of the vagus nerve for fever and neutrophil migration induced by intraperitoneal LPS injection. Inflamm Res 2003; 52: 291-6.

24. Schoener EP, Frankel HM. Effect of hyperthermia and $\mathrm{PaCO}_{2}$ on the slowly adapting pulmonary stretch receptor. Am J Physiol 1972; 222(1):68-72.

25. Žila I, Čalkovská A, Mokrá D, Javorka M, Pullman R st., Javorka K. LPS a nervová regulácia dýchania. Nové poznatky v respirológii. Jesseniova lekárska fakulta Martin 2010; s. 35-39.

26. Plitman JD, Snapper JR. Effects of endotoxin on airway function. In: Brigham KL (Ed.) Endotoxin and the lungs, Marcel Dekker, New York 1994; pp. 133-52.

27. Tang GJ, Kou YR, Lin YS. Peripheral neural modulation of endotoxin-induced hyperventilation. Crit Care Med 1998; 26: 1558-63.

28. Orr JA, Shams H, Karla W, Peskar BA, Scheid P. Transient ventilatory responses to endotoxin infusion in the cat are mediated by thromboxane A2. Respir Physiol 1993; 93: 189-201.

29. Yang YL, Tang GJ, Kou YR. Mediator mechanisms of the airway inflammation during the early phase of endotoxemia in guinea pigs. FASEB J 2000; 14: A604.

30. Jarreau PH, D’Ortho MP, Boye V, Harf A, Macquin-Mavier I. Effects of capsaicin on the airway responses to inhaled endotoxin in the guinea pig. Am J Respir Cell Mol Biol 1994; 149: 128-33.

31. Long NC, Frevert CW, Shore SA. Role of C fibres in the inflammatory response to intratracheal lipopolysaccharide. Am J Physiol 1996; 271: L425-L431.

32. Lai CJ, Ho CY, Kou YR. Activation of lung vagal sensory receptors by circulatory endotoxin in rats. Life Sci. 2002; 70(18):2125-38.

33. Forster HV, Smith CA. Contributions of central and peripheral chemoreceptors to the ventilatory response to $\mathrm{CO}_{2} / \mathrm{H}^{+}$. J Appl Physiol 2010; 108: 989-94.

34. Tabatabai M. Respiratory and cardiovascular responses resulting from heating medulla oblongata in cats. Am J Physiol 1972; 222: 1558-64.

35. Paintal AS. The responses of chemoreceptors at reduced temperatures. J Physiol 1971; 217: 1-18.

36. McQueen DS, Eyzaguirre C. Effects of temperature on carotid chemoreceptor and baroreceptor activity. J Neurophysiol 1974; 37: 1287-96.

37. Baron M, Eyzaguirre C. Thermal responses of carotid body cells. J Neurobiol 1975; 6: 521-527.

38. Baron M, Eyzaguirre C. Effects of temperature on some membrane characteristics of carotid body cells. Am J Physiol 1977; 233: C35-C46.

39. Alcayaga J, Sanhueza Y, Zapata P. Thermal dependence of chemosensory activity in the carotid body superfused in vitro. Brain Res 1993; 600: 103-11.

40. Landauer RC. Pepper DR, Kumar P. Interaction of temperature and $\mathrm{CO}_{2}$ in the adult rat carotid body, in vitro. J Physiol 1995;489P: 162P-163P.

41. Cunningham DJC, O`Riordan JLH. The effect of a rise in the temperature of the body in the respiratory response to carbon dioxide at rest. Q J Exp Physiol 1957; 42: 329-45.

42. Widdicombe JG, Winning A. Effects of hypoxia, hypercapnia and changes in body temperature on the pattern of breathing in cats. Respir Physiol 1974; 21: 203-21.

43. Maskrey M. Body temperature effects on hypoxic and hypercapnic responses in awake rats. Am J Physiol 1990; 259: 492-98.

44. Cherniack NS, von Euler C, Homma I, Kao FF. Graded changes in central chemoceptor input by local temperature changes on the ventral surface of medulla. J Physiol 1979; 287: 191-211.

45. Jennings DB, Laupacis A. The effect of body warming on the ventilatory response to $\mathrm{CO}_{2}$ in the awake dog. Respir Physiol 1982; 49: 355-69.

46. Baker JF, Goode RC, Duffin J. The efect of a rise in body temperature on the central-chemoreflex ventilatory response to carbon dioxide. Eur J Appl Physiol 1996; 72: 537-41.

47. White MD. Components and mechanisms of thermal hyperpnea. J Appl Physiol 2006; 101: 655-63.

48. Zila I, Brozmanova A, Javorka M, Calkovska A, Javorka K. Effects of hypovolemia on hypercapnic ventilatory response in experimental hyperthermia. J Physiol Pharmacol 2007; 58 (suppl. 5); $781-90$. 
49. Waldrop TG, Mullins DC, Millhorn DE. Control of respiration by the hypothalamus and by the feedback from contracting muscles in cats. Respir Physiol 1986; 64: 317-28.

50. Wunnenberg W, Baltruschat D. Temperature regulation of golden hamster during acute hypercapnia. J Therm Biol 1982; 7: 83-6.

51. Berquin P, Bodineau L, Gros F, Larnicol N. Brainstem and hypothalamic areas involved in respiratory chemoreflexes: a Fos study in adult rats. Brain Res 2000; 28: 30-40.

52. Honda Y. Role of carotid chemoreceptors in control of breathing at rest and in exercise: studies on human subjects with bilateral carotid body resection. Jpn J Physiol 1985; 35: 535-44.

53. Dupré RK, Hicks JW, Wood SC. Effect of temperature on chemical control of ventilation in Mexican black iguanas. Am J Physiol 1989; 257: R1258-63.

54. Bonora M, Gautier H. Effects of hypoxia on thermal polypnea in intact and carotid body-denervated conscious cats. J Appl Physiol 1989; 67(2): 578-83.

55. Watanabe T, Kumar P, Hanson MA. Effect of ambient temperature on respiratory chemoreflex in unanaesthetized kittens. Respir Physiol 1996; 106: 239-46.

56. Zila I, Brozmanova A, Javorka K, Javorka M, Calkovska A, Petraskova M. Chemical control of breathing in anaesthetized rabbits during hyperthermia and its recovery by body surface cooling. Acta Med Mart 2003; 1: 10-14.

57. Natalino MR, Zwillich CW, Weil JV. Effects of hyperthermia on hypoxic ventilatory response in normal man. J Lab Clin Med 1977; 89: 564-72.

58. Petersen ES, Vejby-Christensen H. Effects of body temperature on ventilatory response to hypoxia and breathing pattern in man. J Appl Physiol 1977; 42(4): 492-500.

59. Severinghaus J, Powell FL, Hornbein T, Dempsey JA. Proposed consensus methods of measuring human hypoxic ventilatory response at sea level. The 14th International Hypoxia Symposium, edited by Hackett P, Roach R, Lake Louise, Alberta, Canada, 2005; 57 p.

\section{Acknowledgement}

This work was supported by project "Center of Experimental and Clinical Respirology" No. 26220120004, cofinanced from EU sources

Received: February, 21, 2011

Accepted: March, 12, 2011 